\title{
LOS ENTALLES DE SEGOBRIGA Y SU TERRITORIO
}

\author{
POR \\ ROSARIO CEBRIÁN FERNÁNDEZ \\ Parque Arqueológico de Segóbriga
}

\begin{abstract}
RESUMEN
Este artículo se dedica al estudio de los entalles documentados en las excavaciones arqueológicas de la ciudad romana de Segobriga (Conventus Carthaginensis, Saelices, Cuenca). El conjunto está formado por doce entalles, grabados en cuarzo y pasta de vidrio, que representan preferentemente imágenes de carácter religioso.
\end{abstract}

\section{SUMMARY}

Study of engraved gems found in the archaeological excavations in the Roman city of Segobriga (Conventus Carthagunensis, Saelices, Cuenca). This group is made up of twelve gems, best representing sacred images. All of them are engraved either in quartz or in glass paste.

PALABRAS CLAVE: Glíptica romana. Entalles. Segobriga.

KEY WORDS: Roman glyptic. Engraved gems. Segobriga

En los últimos años, las intervenciones arqueológicas en Segobriga (Conventus Carthaginensis, Saelices, Cuenca) han permitido conocer con bastante exactitud la estructura urbana de la antigua ciudad romana. Las campañas de excavaciones del período 2000-2005 en el centro monumental de la ciudad han documentado la totalidad del foro municipal, compuesto por una plaza rodeada por pórticos, tabernae, curia, un edificio con exedra y la basílica. Entre los hallazgos destaca el descubrimiento de la inscripción con letras de bronce del pavimento de la plaza forense y un conjunto de estatuas fechado en época julio-claudia, que formó parte de uno de los ciclos estatuarios del foro dedicados al emperador y su familia y que se halló en el interior de la basílica jurídica ${ }^{1}$.

Entre los materiales arqueológicos recuperados en las excavaciones de Segobriga contamos con un conjunto de siete entalles y una marca de impresión de entalle documentada en una pesa de telar ${ }^{2}$. A este número hay que aña-

\footnotetext{
1 Los últimos descubrimientos en el foro de Segobriga pueden verse en Abascal, Cebrián y Trunk 2004, 219-256 con toda la bibliografía anterior. Una primera aproximación a los hallazgos escultóricos del foro de la ciudad en Noguera, Abascal y Cebrián 2005, 53-61.

2 Cinco de ellos han sido hallados en las excavaciones recientes realizadas en el foro de Segobriga $\left(\mathrm{n}^{\circ}\right.$ 2, 4, 5, 6 y 12 del catálogo).
}

dir cuatro más, de los cuales dos se encontraron en el paraje conocido como Los Enebrales, situado en una zona elevada al noreste de Segobriga, y en el que destaca el hallazgo de numerosas balas de honda realizadas en plomo. Un tercero procede del término municipal de Saelices, sin que podamos determinar el lugar concreto donde apareció y el último se halló en el municipio de El Hito (Cuenca). Con la excepción de dos entalles de Segobriga, que se encontraron en el nivel superficial del Foro y de las Termas Monumentales (núm. 2 y 3), los cinco restantes (núm. 1, $4,5,6$ y 7) han aparecido dentro de un contexto arqueológico, lo que nos permite conocer su cronología ante quem.

\section{CATÁLOGO ${ }^{3}$}

1.- Dos gallos enfrentados Siglo II-III d.C.

Pasta vítrea de color azul. Forma redondeada. Cara superior convexa y la inferior plana.

Medidas: $1,7 \times 1,5 \times 0,2 \mathrm{~cm}$.

$\mathrm{N}^{\mathrm{o}}$ inventario: Puerta E./Área I/ Nivel II/Sector IV Procedencia: Anfiteatro

Iconografía: Representación de dos gallos enfrentados. El gallo que está grabado a la izquierda tiene la cabeza inclinada hacia el suelo y el otro mira hacia arriba mientras pisa con la pata derecha la cabeza del primero. Debajo línea de base.

La imagen del gallo aparece ya en monedas de Hime$r a$ (Sicilia, Italia) del siglo VI a.C., aludiendo al nacimiento del día. Este motivo pervive con diversos simbolismos en el mundo romano, donde una pareja de gallos en actitud de lucha se utiliza para representar el carácter guerrero y sirve como alegoría de la victoria. P. Bruneau considera que el tema de la lucha de gallos fue muy bien acogido en el mundo funerario al evocar la victoria sobre la muerte, la inmortalidad. Además, señala que el motivo del combate de gallos se repite con frecuencia en época imperial en contextos funerarios, apareciendo esta escena en altares, sarcófagos, estelas y bajo-relieves ${ }^{4}$. Por otro

\footnotetext{
3 Las fotografías de los entalles aparecen al doble de su tamaño para facilitar la visión de la imagen grabada y cada una de las piezas del catálogo cuenta con el dibujo del perfil de su forma.

4 Bruneau 1965, 115-120.
} 
lado, los combates de gallos tienen su origen en el mundo oriental pero continuaron en época romana, asociados a competiciones atléticas. En ocasiones, la representación de dos gallos enfrentados aparece acompañada de una hoja de palma como símbolo del triunfo, con ejemplos en varios mosaicos de Pompeya, entre otros ${ }^{5}$. Llama la atención la aparición del tema de este entalle en el anfiteatro de Segobriga, lugar donde pudieron llevarse a cabo estas luchas de gallos con espectadores y alejando la posibilidad de un carácter funerario de la pieza.

Paralelos en glíptica: Sena Chiesa 1966, n 1341; Schlüter et alii 1975, n 1242, Taf. 169 (Hannover); Maaskant 1978, no 153, no 1069; Riha 1990, no 56 (en pasta vítrea) y no 57 ; Guiraud 1995, n 46.

Datación: Su hallazgo se produjo en 1982 durante la excavación de la puerta oriental de entrada al anfiteatro, construido entre el 30-60 d. C. e inaugurado hacia el $78 \mathrm{~d}$. C. en época de Tito y Vespasiano. El anfiteatro estuvo en uso hasta finales del siglo III d. C., momento en el que se produce el incendio de parte del edificio ${ }^{6}$. Los paralelos de este entalle se fechan a partir del siglo II a. C. y continúan hasta el siglo III d. C. En el caso del ejemplo de Segobriga proponemos una cronología entre los siglos II-III d. C., atendiendo a las fechas de construcción y uso que ha proporcionado el edificio donde se halló y al empleo de la pasta vítrea en su realización, documentada arqueológicamente en Segobriga en contextos tardíos ( $n^{\circ} 7$ del catá$\log 0$ ).

\section{2.- Bonus Eventus con clámide} Siglo II d.C.

Jaspe de color rojo. Forma ovalada. Ambas caras planas y lados cortados hacia el reverso. La superficie presenta varios desconchones en la parte inferior izquierda.

Medidas: $1,4 \times 1 \times 0,2 \mathrm{~cm}$.

$\mathrm{N}^{\circ}$ inventario: 03/5000/3194

Procedencia: Foro

Iconografía: Figura masculina desnuda, de pie y hacia la izquierda. Lleva clámide, cuyos extremos le caen por la espalda desde los hombros. La pierna

\footnotetext{
5 Pugliese et alii, 1994, 45 y fig. 74, con representación de un combate de gallos en un gimnasio. Al fondo de la escena aparecen dos jóvenes victoriosos, uno con corona de laurel y otro con hoja de palma. Junto a ellos se sitúan otros dos personajes cabizbajos que representan a los propietarios del gallo perdedor. El emblema de este mosaico pertenece a uno de los triclinios de la Casa del Laberinto, Regio VI, Insula 11 de Pompeya.

6 Almagro-Abascal 1999, 86-88.
}

derecha aparece ligeramente flexionada. En la mano derecha lleva una bandeja con alguna ofrenda, mientras que en la izquierda desconocemos lo que sujeta por rotura de la pieza pero, tal vez, un ramo de uva o espiga de trigo.

La representación del Bonus Eventus es muy frecuente en monedas y gemas a partir del período tardorepublicano. Es una divinidad romana, que simboliza la prosperidad y el buen auspicio para la consecución de cualquier fin ${ }^{7}$. El testimonio más antiguo en las fuentes literarias es el de Varrón que cita al Bonus Eventus como divinidad protectora de la agricultura (rust. I, I, 6). Más tarde, Plinio menciona que existían dos estatuas de esta divinidad en el Capitolio de Roma: la primera, obra de Euphranor (NH XXXIV, 77) y la segunda de Praxíteles (NH XXXVI, 23). Su imagen aparece en la numismática por primera vez en el denario de Scribonius Libo en el 62 a.C. (Crawford, $R R C, \mathrm{n}^{\circ} 416$, tav. 51). A partir de ese momento la figura del Bonus Eventus, acompañada de su nombre, se graba en los reversos de algunas series monetales de Galba, Tito, Trajano y Caracalla, entre otros. La imagen más difundida del Bonus Eventus es la que conocemos a través de la glíptica, en la que el dios lleva clámide sobre la espalda, en una mano un cesto con fruta y en la otra una espiga de trigo ${ }^{8}$.

Paralelos en glíptica: Fernández-Chicarro 1953, no 8; Sena Chiesa 1966, no 541-552; Zazoff 1970, no 51, Taf. 7 (Braunschweig), no 99, Taf. 37 (Göttingen); Henil 1974, no 188-195; Schlüter et alii 1975, n 918 , Taf.. 120 (Hannover); Sena Chiesa 1978, n $\mathrm{n}^{\circ} 77$; Maaskant 1978, no 598-600; Zwierlein-Diehl 1979, $\mathrm{n}^{\circ}$ 1322-1331; Zazoff 1983, no 231; Platz-Horster 1984, no 95; Krug 1995, no 33 y 84; Casal 1990, n $^{\circ}$ 287; López 1990, n 111; Zwierlein-Diehl 1998, $\mathrm{n}^{\circ}$ 200; Gesztelyl 2000, n 160; Spier 2001, nº 39.

Datación: Este entalle se localizó en el nivel superficial del Foro en la campaña de excavaciones del año 2003 y, por tanto, apareció descontextualizado. Las piedras opacas, entre ellas el jaspe, se utilizaron como materia prima para la realización de entalles, preferentemente, en el siglo II d.C ${ }^{9}$. Por otro lado, la representación del Bonus Eventus comienza a difundirse entre la población a partir de la segunda mitad del siglo I a. C. cuando su imagen aparece en monedas de plata. En Hispania, será a partir del 68 d. C. cuando se popularice al aparecer el nombre del dios

\footnotetext{
7 Arias, P. E., Lexicon, vol. III.1, 1986, 123-126 y vol. III.2, 98-99 con imágenes del Bonus Eventus en la glíptica ( $\left.\mathrm{n}^{\text {o }} 2-5\right)$ y en la numismática ( $n^{\circ}$ 6-18).

8 Spier 2001, 67.

9 Henig 1974, 41-42.
} 
junto con su imagen en los reversos de algunos denarios del emperador Galba ${ }^{10}$. El tema representado en este entalle permite proponer una cronología del siglo II d. C.

\section{3.- Bonus Eventus}

Segunda mitad del siglo II d.C.

Ónice. Entalle en anillo de bronce. Forma oval. Ambas caras planas y lados cortados hacia el anverso.

Medidas: $0,9 \times 0,6 \times[-] \mathrm{cm}$.

$\mathrm{N}^{\mathrm{o}}$ inventario: 95/sup./detrás ermita

Procedencia: Termas Monumentales

Iconografía: Representación del Bonus Eventus. El dios está de pie, la cabeza girada hacia la derecha. Lleva unas espigas de trigo en su mano derecha y brazo extendido hacia abajo. Con su mano izquierda sujeta una pátera, con brazo elevado hasta los hombros. El cuerpo del dios se representa desnudo y ligeramente contorneado. La cabeza aparece cubierta por un gorro con visera. Línea de suelo.

Para esta imagen del Bonus Eventus se copió el modelo de la estatua de Triptolemo, obra de Eufranor, siguiendo el texto de Plinio, en el que dice que el dios llevaba en su mano derecha una pátera y en la izquierda unas espigas ${ }^{11}$. Su representación aparece en los reversos de algunas monedas acuñadas en época de Trajano y Adriano ${ }^{12}$.

Paralelos en glíptica: Sena Chiesa 1966, nº 524-537; Zazoff 1970, n 100- Taf. 37 (Göttingen); Sena Chiesa 1978, $n^{\circ} 77$; Maaskant 1978, n ${ }^{\circ}$ 522, 601, 933, 950; Zwierlein-Diehl 1979, $\mathrm{n}^{\circ}$ 1320; Casal 1990, $\mathrm{n}^{\circ}$ 285; López 1990, n 105 y 107; Krug 1995, nº 82; Guiraud 1988, n 227-228.

Datación: La pieza apareció en 1995 en un nivel superficial de las termas monumentales, en un área utilizada como vertedero para arrojar las cenizas de los hornos empleados para calentar algunas de sus estancias. Para establecer la cronología de esta pieza contamos con el anillo de bronce en el que se encuentra engarzado el entalle con la imagen del Bonus Eventus. Presenta forma elíptica, con cara superior oval y con engarce del entalle tam-

\footnotetext{
${ }^{10}$ Arias, P. E., Lexicon, vol. III.1, 1986, 124-125 con la descripción de las monedas acuñadas en época imperial con la imagen del Bonus Eventus, en las que se incluyen los denarios acuñados en Hispania bajo el emperador Galba.

${ }^{11}$ Plinio, NH XXXIV, 77: simulacrum Boni Eventus, dextra pateram, sinistra spicam et papavera tenens.

${ }^{12}$ Casal 1990, 142.
}

bién oval, que sobresale del anillo (fig. 1. 3). M. Henig estableció una tipología de los anillos a partir de los entalles estudiados en Gran Bretaña con un total de 15 formas. El tipo VI de Henil se corresponde con el anillo en el que se engarzó nuestra pieza. Presenta una cronología del siglo III d. C., aunque hay ejemplos que se sitúan en la segunda mitad del siglo II ${ }^{13}$. Esta datación coincide con la tipología elaborada por H. Guiraud para los entalles y camafeos de la Gallia ${ }^{14}$. La imagen del Bonus Eventus y la datación del anillo aconsejan una cronología de la segunda mitad del siglo II d. C.

\section{4.- Atenea-Minerva oferente} Siglo I-II d.C.

Cuarzo de color rojo. Forma oval. Ambas superficies planas con los lados cortados hacia el reverso.

Medidas: $0,8 \times 0,7 \times 0,2 \mathrm{~cm}$.

$\mathrm{N}^{\mathrm{o}}$ inventario: 03/7240/797/20.

Procedencia: Foro

Iconografía: La figura femenina representada está de pie y de frente, con la cabeza vuelta hacia la derecha mirando la pátera que sostiene con su mano izquierda y brazo extendido. Viste una larga túnica y lleva el casco de visera rematado por una larga cimera radiada, característico de las representaciones de Atenea. El brazo derecho, también extendido, se apoya en el escudo ovalado que está en el suelo. Por detrás de el escudo, sobresalen dos puntas de lanza ${ }^{15}$.

Se trata de la representación de Atenea-Minerva, una imagen de gran difusión en época de Augusto y que perdura en períodos posteriores. Repite el esquema compositivo de la Atenea Parthenos de Fidias (circa 440 a.C.), una colosal estatua de oro y marfil. En esta escultura la diosa aparece de pie, con el escudo apoyado en su lanza y con su mano dere-

\footnotetext{
${ }^{13}$ Henig 1974, 49 y fig. 2.

${ }^{14}$ Guiraud 1988, 79, tipo 2d, con una cronología entre la segunda mitad del siglo II y la primera mitad del III d. C. Por su parte, N. Ergün (1999, 713-725, lám. 3) ha establecido una tipología de los casi 500 anillos con gemas de la colección del museo de Colonia. En esta clasificación, la pieza $\mathrm{n}^{\circ} 3$ de nuestro catálogo correspondería al tipo 2.6, con la misma cronología. En este mismo artículo, puede verse la imagen escultórica del magistrado L. Poblicius, que lleva dos anillos con entalles en su mano derecha, que utilizó para autentificar documentos oficiales (lám 1).

${ }^{15}$ Canciani, F., Lexicon, 1984, vol. II.1, 1082, n 106 con imagen de Minerva de pie y con pátera en un entalle procedente de Mónaco y fechado en época de Augusto.
} 
cha sujeta una pequeña victoria. La figura de Minerva oferente es muy frecuente en las estatuillas de bronce de carácter votivo fechadas en época republicana ${ }^{16} \mathrm{y}$ en la numismática del período helenístico y romano ${ }^{17}$.

Paralelos en glíptica: Sena Chiesa 1966, n 117; Sena Chiesa 1978, no 51; Maaskant 1978, n 854; Mandrioli 1987, $\mathrm{n}^{\circ}$ 134; Casal 1990, n 200; PlatzHorster 1994, n 220, Zwierlein-Diehl 1998, n 216219; Guiraud 1988, nº 85.

Datación: El entalle se localizó en la zona de acceso al Foro, junto al kardo maximus, en el interior de una de las viviendas de época tardo-romana que reocupó el espacio que permitía acceder a la plaza forense a través de una escalera monumental. Apareció junto a un sólido del emperador Arcadio, acuñado en Constantinopla en el año 383 d.C. La presencia de esta moneda fecha el estrato arqueológico en un momento posterior al siglo IV d.C., lo que evidencia que este entalle fue guardado por su dueño y descendientes durante mucho tiempo ${ }^{18}$. La representación de Atenea-Minerva en la glíptica aparece con mucha frecuencia en época republicana y continúa a lo largo del siglo I d. C., aunque conocemos algunos ejemplos en colecciones europeas de la imagen de la diosa oferente fechados en el siglo II d. C. ${ }^{19}$. El grabador simplificó la representación de Minerva, utilizando trazos lineales y acentuando la separación entre las distintas

\footnotetext{
${ }^{16}$ Las imágenes en la glíptica de Atenea-Minerva están inspiradas en tipos estatuarios, como la Atenea Parthenos y Promachos. La Atenea Promachos armada constituirá la representación clásica de la diosa. Poco a poco, la figura se irá transformando y diversificando con la aparición de nuevos atributos. Entre las representaciones derivadas de este tipo se encuentra la de Atenea llevando pátera en su mano derecha y lanza en la izquierda, documentada en dos estatuillas de bronce halladas en Esparta, véase Demargne, P. Lexicon, vol. II.1, 1984, 974975 y vol II.2, 1984, Taf. 726, $\mathrm{n}^{\circ} 185$. Durante los siglos III-II a. C., la imagen de Minerva oferente (con lanza en mano izquierda, pátera en la derecha y casco corintio) aparece con frecuencia en las estatuillas de bronce de carácter votivo, véase Colonna, G., Lexicon, vol. II.1, 1984, 1059 y vol. II.2, 1984, Taf. $777, \mathrm{n}^{\circ} 119$ h. Esta representación de Minerva debió servir de modelo a los grabadores de gemas, aunque la imagen no se difundió tanto como la de Atenea-Minerva con Victoria.

${ }^{17}$ La bibliografía sobre las monedas con la imagen de Atenea Promachos puede verse en Pannuti 1983, 14-15.

${ }^{18}$ Los entalles y camafeos tuvieron un alto valor en época romana e incluso fueron objeto de coleccionismo por parte de las clases sociales más elevadas, lo que además de aumentar su valor económico provocó que aquel que poseía una de estas piezas lo llevase consigo durante muchos años y se transmitiese a sus descendientes como piezas de valor y de recuerdo. Sobre el tema, Henig 1983, 152

19 Zwierlein-Diehl 1998, 317-318.
}

partes del cuerpo y evitó dar movimiento a la larga túnica que viste. La cronología de la pieza podría situarse entre finales del siglo I y el siglo II d. C.

\section{5.- Águila con corona civica} Adriano-Antonino Pío (117-161 d. C.)

Cornalina. Forma redondeada. Cara superior ligeramente convexa y cara inferior cóncava.

Medidas: $1,1 \times 0,8 \times 0,2 \mathrm{~cm}$.

$\mathrm{N}^{\circ}$ inventario: 03/7392/577/24.

Procedencia: Taberna $\mathrm{n}^{\circ} 5$ situada junto al Pórtico Meridional del Foro.

Iconografía: Representación de un águila con las alas desplegadas y con la cabeza vuelta hacia la derecha. Sujeta con el pico una corona de laurel. Con el ala izquierda envuelve una corona civica. Línea de base. El águila es el ave del dios Júpiter. En época imperial, este motivo se repite con frecuencia en la numismática ya que representa el poder y la fuerza del emperador, convirtiéndose en emblema imperial. Hacia el 27 a. C. se acuñan en Asia Menor áureos en honor de Augusto, en cuyo reverso se representa el águila de Júpiter con la corona cívica llevándola en las garras y detrás, los laureles. En 19/18 a.C., Augusto aparece en las monedas llevando la corona de roble, que le había sido concedida ob cives servatos ${ }^{20}$. A partir de entonces, esta corona se convirtió en símbolo de poder reservado exclusivamente a los emperadores, olvidado ya su antiguo significado en el que la corona civica se concedía por la salvación de un conciudadano.

Paralelos en glíptica: Sena Chiesa 1966, no 1259 y 1261; Maaskant 1978, $\mathrm{n}^{\circ} 828, \mathrm{n}^{\circ} 1000 \mathrm{a}, \mathrm{n}^{\circ} 1066 \mathrm{~b}$; Zwierlein-Diehl 1979, nº 1919-1936; Pannuti 1983, $\mathrm{n}^{\mathrm{o}}$ 271-274 (águila sobre globo, entre dos insignias y con corona en el pico ( $\left.\mathrm{n}^{\circ} 272\right)$, sobre capitel); PlatzHorster 1994, $n^{\circ}$ 172-179; Gesztelyi 2000, $n^{\circ} 218$; Humer 2004, p. 68.

Datación: La imagen del águila imperial se repite con frecuencia en gemas realizadas entre finales del siglo I a.C. y el siglo I d.C ${ }^{21}$. Por la cercanía a Segobriga, destacamos el hallazgo en Valeria (Valera de Abajo, Cuenca) de un entalle de jaspe rojo, con representación de un águila con las alas cerradas, aunque no lleva la corona en el pico $^{22}$. Destaca el gran esquematismo de la figura, provocado por la técnica empleada en su ejecución, mediante un taladro de rueda, que produce un rayado. Este tipo de grabado es característico de la

\footnotetext{
${ }^{20}$ Zanker 1992, 119.

${ }^{21}$ Casal 1990, 48 con la bibliografía sobre el tema.

${ }^{22}$ Osuna 1977, 156
} 
época de Augusto y del período julio-claudio ${ }^{23}$. Este entalle se halló en uno de los rellenos de nivelación de los recintos posteriores de la taberna número 5, situadas en el costado meridional del foro de Segobriga. La cronología del material arqueológico del nivel donde apareció (UE 7392) se sitúa en época de AdrianoAntonino Pío, que sirve para fechar el entalle ${ }^{24}$.

\section{6.- Escena con sátiro}

Segunda mitad I d.C.- primera mitad II d. C.

Cornalina. Forma redondeada. Cara superior ligeramente cóncava e inferior plana. Lados cortados hacia el reverso.

Medidas: $1,1 \times 0,9 \times 0,15 \mathrm{~cm}$.

$\mathrm{N}^{\mathrm{o}}$ inventario: 02/5758/34

Procedencia: Foro

Iconografía: La escena representada se compone de un personaje sentado, de perfil y mirando hacia la derecha. Forma parte de su vestimenta un cordón que le ciñe la cintura y cuyos extremos aparecen representados en la espalda. Con las manos sujeta un objeto circular. Su pierna derecha está flexionada en ángulo recto, mientras que la izquierda está ligeramente adelantada. Detrás del personaje aparece un tirso. Enfrente de él, un herma de Príapo sobre una columna alta y al lado un ánfora. Línea de base.

Paralelos en glíptica: Sena Chiesa 1966, n 372; Zazoff 1970, nº 96, Taf. 12 (Braunschweig); Schlüter et alii 1975, $\mathrm{n}^{\circ}$ 871-872, Taf. 113 (Hannover);

\footnotetext{
${ }^{23}$ Casal 1990, 52

${ }^{24}$ La cronología de la UE 7392 corresponde al siglo II d. C. El conjunto cerámico hallado en este nivel es el siguiente: TSG: Drag. 15/17, 18, 24/25, 29b, Hermet 18?; TSH: Hisp. 2, 5, 7 20, 51, Drag. 15/17, 27, 30, 36, 37 a y b, 44, Ritt. 8; TSH brillante: Forma 9, forma 13 y forma 15?; Vidriada: similar a un vasito con decoración de hojas de piña (tipo Lattara 6 Gla-Ro 1a); Paredes Finas: Decoración arenata y a barbotina. Mayet XXXVII?; Ánforas: Dressel 2-4, Beltrán IIb y ánfora rodia?; Lucernas: Deneauve VIIb (con marca, ex ofi $q$ sem), lucernas mineras. El arqueólogo D. Sanfeliu que realizó el inventario de los materiales aparecidos en la campaña de excavaciones arqueológicas en Segobriga durante el año 2003 considera que la cronología inicial que se baraja para este nivel corresponde a la época de Adriano, en función de la marca de officina de la lucerna ( $2^{\circ}$ cuarto del siglo II d. C. en Deneauve 1974, 187, similar $n^{\circ} 870$ ), y la asociación con el resto de cerámica. No obstante, es muy posible que se trate más bien de un conjunto de época antonina. Un claro ejemplo es la cerámica de cocina (piezas $n^{\circ}$ 287-303), algunas de las cuales imitan claramente la forma Lamb 10a/Hayes 23b (Aquilué 1985, 212). Por otro lado, el tipo de piezas es bastante similar a fig. 31, 4 de UE 11002 de Lorrio 2001, 53-54.). Una situación similar se repite con las marmitas inventariadas en esta unidad, que recuerdan a los caccabus africanos (Aquilué 1985, 212).
}

Maaskant 1978, no 343, n 358; Casal 1990, n 82; Gesztelyi 2000, no 34 (sin ánfora).

Datación: El entalle apareció durante la excavación del pórtico meridional del foro en un relleno de tierra de color marrón oscura, muy compacta, que contenía gran cantidad de tejas y fragmentos de mármol (UE 5758). El nivel arqueológico en el que apareció la pieza se corresponde con el momento de expolio del foro de la ciudad, fechado en época tardo-romana ${ }^{25}$. Por ello, los datos con los que contamos para datar el entalle están relacionados con la técnica de fabricación, ya que ni el material empleado ni el tema elegido ayudan a aproximarnos a su cronología ${ }^{26}$. La escena con sátiro aparece en una de las gemas de la colección de Aquileia, fechada por G. Sena Chiesa a finales del siglo I o inicios del II d. C. atendiendo al criterio estilístico del modelado de los detalles ${ }^{27}$. En las colecciones de los museos de Hannover se conservan dos entalles que repiten el esquema compositivo que el ejemplo de Segobriga y que tienen una cronología del siglo I d. $\mathrm{C}^{28}$. Esta pieza presenta un trabajo minucioso en los detalles. Se utiliza la traza redondeada en los objetos representados y la imagen del sátiro se muestra bien modelada, aunque las distintas partes del cuerpo aparecen muy rígidas al no presentar ningún detalle interior. La tendencia estilística utilizada en el grabado de esta pieza aconseja una cronología de la $2^{\mathrm{a}}$ mitad del siglo I o primera mitad del siglo II d. C. ${ }^{29}$.

7.- Personaje corriendo Siglo III d.C.

Pasta vítrea de color violáceo. Forma redondeada. Cara superior plana e inferior cóncava, con bordes curvados cortados hacia el anverso. Presenta una rotura en la parte izquierda.

${ }^{25}$ La UE 5758 se fecha entre el siglo IV-V d.C., y más probablemente en la segunda mitad del siglo IV. En este período se puede datar el borde de plato de terra sigillata clara C Hayes 50b (350-400 d. C.) y con una cronología no tan precisa un borde de un plato de T.S. Hispánica Tardía, junto con algún ejemplo de Drag. 37 decorada de esta misma producción.

${ }^{26} \mathrm{El}$ empleo de la cornalina para la talla de entalles y camafeos fue muy habitual a lo largo del período imperial, aunque su uso fue mayor en el siglo II d. C., véase Henig 1974, 41-42. Los sátiros acompañan en numerosas representaciones al dios Dionisios o aparecen con objetos relacionados con el vino: cráteras, ánforas, cántaros y situlae. El origen de su representación en la glíptica se encuentra en la estatuaria helenística. Sobre el tema, Arias, P. E.(1966), Encicl. Arte Antica, s. v. Satiri e Sileni, 67-73.

27 Sena Chiesa 1966, 184-185.

28 Schlüter 1975, 176.

${ }^{29}$ Este entalle se incluye en la tendance classique linéaire definida por H. Guiraud para la Gallia (1988, 48-50). 
Medidas: 1,2 x $[0,9]$ x $0,3 \mathrm{~cm}$.

$\mathrm{N}^{\mathrm{o}}$ inventario: 00/ 6123/11

Procedencia: Necrópolis tardo-romana.

Iconografía: Se representa a una figura masculina desnuda, corriendo hacia la izquierda. La pierna izquierda aparece hacia atrás y la derecha flexionada y adelantada hacia el frente. Los brazos se representan en la misma posición.

Hemos encontrado similitudes con un entalle perteneciente a la colección del Museo Arqueológico Nacional, en el que se define al personaje representado como un atleta ${ }^{30}$.

Paralelos en glíptica: Casal 1990, nº 369.

Datación: El entalle apareció formando parte del ajuar de un enterramiento femenino de la necrópolis tardoromana de Segobriga ${ }^{31}$, fechado entre mediados del siglo IV y principios del siglo $\mathrm{V} \mathrm{d}$. $\mathrm{C}^{32}$. El contexto arqueológico en el que apareció la pieza y la tendencia al esquematismo de la imagen grabada nos lleva a proponer una cronología a partir del siglo III d. C.

\section{8.- Cabeza de Pan} Siglo I d.C.

Jaspe de color rojo. Forma oval. Ambas superficies planas y perfil cortado hacia el reverso.

Medidas: $1,1 \times 0,9 \times 0,2 \mathrm{~cm}$

$\mathrm{N}^{\mathrm{o}}$ inventario: colección privada.

Procedencia: Los Enebrales (Saelices, Cuenca).

Iconografía: Cabeza masculina en perfil izquierdo. En la cabeza lleva un aderezo que le cubre la frente y las orejas, rematado por dos cuernos de cabra. Los rasgos del rostro están muy bien definidos: nariz recta, ojo amplio y muy marcado, labios gruesos y barbilla destacada. El perfil del rostro sigue modelos griegos.

La representación del dios griego Pan, hijo de Hermes y de la ninfa Dryops, es frecuente a partir del siglo V a. C., cuando se introduce su culto en Atenas ${ }^{33}$. Generalmente se le representa con rostro barbado, lleno de

${ }^{30}$ Casal 1990, 162.

31 El ajuar de la Tumba 50 ( $n^{\circ}$ inventario 00/6123/1 al 8) está formado por anillo de bronce, dos alfileres de bronce, aguja de plata para el cabello, dos pendientes de plata y un nummus de Constantino acuñado en la officina $1^{\text {a }}$ de Londinium, 320 d.C. (RIC VII, 168). Entre otros objetos repartidos por la sepultura se halló este entalle ( $\mathrm{n}^{\mathrm{o}}$ inventario 00/6123/11).

32 Abascal et alii 2004, 423.

${ }^{33}$ El culto al dios Pan se originó en Arcadia (Peloponeso, Grecia) como divinidad protectora de los pastores y sus rebaños. Su figura adquirirá relevancia en 490 a. C. en el contexto de la batalla de Marathon entre Persas y atenienses. Sobre su iconografía puede verse Boardamn, J., Lexicon, VIII.1, 1997, 923-941. arrugas, con dos cuernos de cabra que le nacen de su frente y con sus pies transformados en los de un macho cabrío. Existe otro tipo de representación del dios en la escultura en la que aparece joven, sin barba, con pelo corto y con dos pequeños cuernos en la cabeza ${ }^{34}$. Esta imagen del dios se ampliará con la creación de un Pan femenino, que se documenta ya en algunas monedas de finales del siglo $\mathrm{V}$ a. C. y que aparece asociado a la música y al erotismo ${ }^{35}$. El entalle de Segobriga podría corresponder a esta versión femenina del dios Pan ya que el pelo parece estar recogido en un moño bajo. La presencia de la imagen de este dios en entalles y camafeos del período romano supone un porcentaje muy pequeño si lo comparamos con otras divinidades como Eros, Sátiro, Mercurio, Marte o Victoria ${ }^{36}$. Aunque no faltan ejemplos de gemas con la imagen de Pan, generalmente aparece asociada a alguno de sus atributos característicos como la flauta o syrinx y el bastón o pedum ${ }^{37}$. Son extraños los retratos del dios en los que sólo la presencia de los dos cuernos en la cabeza permite su identificación y cuando aparecen lo hacen acompañados de la imagen de un Sátiro ${ }^{38}$.

Datación: La buena ejecución del entalle nos permite proponer una cronología del siglo I d. C. El retrato de perfil aparece perfectamente encuadrado en la gema. Los rasgos del rostro se muestran muy marcados pero forman un volumen unificado y los trazos del pelo aparecen bien delineados, utilizando una

\footnotetext{
${ }^{34}$ Las representaciones del dios Pan en las distintas manifestaciones artísticas del mundo helenístico y romano pueden verse en Marquardt 1995. Sobre la imagen de Pan joven en la escultura, esta misma autora recoge algunos ejemplos en pp. 139-140; 156-157; 159-169 y Taf. 18, 1-4, con una cronología que se sitúa entre los siglos I- II d. C.

35 En J. Boardman, Lexicon, VIII.1, 1997, 938-939 puede verse las acuñaciones de Grecia, sur de Italia y Sicilia con el retrato de Pan. También recoge algunas representaciones femeninas del dios en vol. VIII. 1, 927 y VIII.2, Taff. 617-618 y considera que una de las primeras imágenes del Pan femenino se encuentra en las acuñaciones de Metaponto (Italia) en el siglo IV a. C. Por su lado, H. Sichterman menciona la creación de una imagen femenina del dios en época romana, documentada en algunos mosaicos de Pompeya, véase Sichtermann 1963, Encicl. Arte Antica, s. v. Pan, 921-922.

36 Guiraud 1988, 22.

37 Algunos ejemplos en Guiraud 1988, nº 313-314 (con syrinx y pedum), $\mathrm{n}^{\mathbf{o}} 315$ (con pedum) y n 316 (con syrinx); Zwierlein-Diehl 1998, n 214 (con pedum); Wagner y Boardman $2003, n^{\circ} 224$ y 386 (con syrinx) y n 387 (con pedum). Por otro lado, su imagen también aparece asociada a una cabra, véase Guiraud 1988, no 317; Brandt 1968, n 285 (y con pedum)

38 Wagner y Boardman 2003, n 364 (cabeza bifronte de Pan joven y Sátiro), con cronología I a. C.-I d. C. Mismo tipo en Zwierlein-Diehl 1969, nº 499 y Zazoff 1970, nº 600.
} 
línea más grueso para distinguir la diadema que lleva en la cabeza del cabello.

\section{9.- Personaje con abacus} Siglo I a. C.- I d. C.

Jaspe verde. Entalle en anillo de hierro. Cara superior convexa e inferior plana.

Medidas: 1 x 1 x $0,2 \mathrm{~cm}$.

$\mathrm{N}^{\mathrm{o}}$ inventario: colección privada.

Procedencia: Los Enebrales (Saelices, Cuenca).

Iconografía: Personaje masculino de avanzada edad y con barba. Se le representa sentado sobre una silla con alto respaldo en perfil izquierdo. La espalda no apoya sobre el respaldo. Viste túnica corta. Aparece con los brazos extendidos mirando un abacus o tabla de cálculo. La pierna izquierda flexionada en ángulo recto mientras que la derecha aparece ligeramente doblada hacia atrás. Línea de base.

Los ábacos tenían grabadas nueve líneas paralelas dispuestas verticalmente que representaban los lugares de valor relativo de un sistema de numeración de base diez y constituyeron el instrumento de suma y resta del mundo romano ${ }^{39}$. Estas tablas de contar fueron empleadas por todo tipo de comerciantes y hombres de negocios para los que su uso fue una necesidad. En el Landesmuseum de Trier se conserva un bajo-relieve funerario de época romana en la que dos tenderos realizan cálculos con el abacus que sujetan, ante la mirada de una tercera persona que les presta su ayuda ${ }^{40}$. Conocemos ejemplos en la glíptica de este tipo de composición en las que el anciano personaje lleva en sus manos un libro, que se identifica con la imagen de un filósofo ${ }^{41}$, pero la representación de un ábaco es extraña. E. Guillaume menciona un entalle conservado en el Cabinet des Médailles de París en el que aparece un hombre sentado calculando con la ayuda de cuentas o calculi, mientras que con su mano izquierda sujeta un ábaco ${ }^{42}$.

\footnotetext{
${ }^{39}$ Sobre el funcionamiento del ábaco en época romana y los ejemplares en bronce que se conservan en la actualidad en distintos museos, puede verse Fellmann 1983, 36-40.

${ }^{40}$ Kretzschmer 1978, 7-8 y lám. 6.

${ }^{41}$ Sobre la identificación en la glíptica de un personaje de avanzada edad y en actitud de lectura con un filósofo, véase Platz-Horster 1984, 107. Esta misma composición, aunque con libro, puede verse en Brandt, I.2, 1970, n 1487, Taf. 144 (München); Zarzoff 1970, nº 390 y 392, Taf. 62 (Göttingen); Schluter et alii 1975, $\mathrm{n}^{\circ}$ 441, Taf. 62 (Hannover); Vollenweider 1979, vol. II, $n^{\circ}$ 2; Platz-Horster 1984, $n^{\circ} 113$ (con columna) y n 143 (con túnica larga) y Wagner-Boardman 2003, nº 395. La cronología de estos entalles se sitúa entre el siglo I a. C. y el siglo I d. C.

${ }^{42}$ Guillaume 1877, Daremberg Saglio, s. v. abacus, 1.
}

Datación: Para aproximarnos a la cronología de este entalle contamos con el anillo de hierro en el que se engarzó (fig. 1.9). Este anillo, de $2 \mathrm{~cm}$ de diámetro exterior, tiene contorno elipsoidal, con fuerte inclinación de las paredes, que presentan una sección planoconvexa y cara superior oblonga. La tipología del anillo tiene una cronología del siglo I d. C. ${ }^{43}$. Por otro lado, la calidad de ejecución de esta pieza también nos permitiría situarlo cronológicamente en el siglo I d. C., ya que el grabador ha cuidado la anatomía del personaje, el drapeado de la túnica y los detalles de la silla. Ahora bien, el estilo del entalle enlaza con la tradición helenística de las representaciones de Sócrates, sobre todo a partir del siglo II a. C. cuando se convierte en el símbolo de aquellos que prefieren una vida dedicada al estudio y alejada de la dureza de la vida activa. A partir de ese momento se generaliza en la glíptica la imagen de un personaje anciano y con barba en actitud de lectura ${ }^{44}$. El propietario del entalle hallado en Segobriga compró un anillo en el que su grabador combinó la idea de serenidad que transmitía la imagen de un filósofo con su profesión, probablemente un comerciante de origen griego, que utilizaba el abacus en su trabajo ${ }^{45}$. Ello nos llevaría a proponer una cronología que se sitúa entre el siglo I a. C y el I d. C., teniendo en cuenta además la forma circular y convexa de la piedra sobre la que fue tallada esta pieza, frecuente en la glíptica de época republicana ${ }^{46}$.

\section{0.- Guerrero con armas ${ }^{47}$} Inicios del siglo I d. C.

Calcedonia-nicolo. Diseño realizado en una capa de color blanco, que destaca sobre fondo de color marrón melado. Forma oval. Ambas superficies planas y perfil cortado hacia el reverso.

Medidas: 1,3 x 1 x 0,4 cm.

$\mathrm{N}^{\circ}$ inventario: colección privada.

Procedencia: Saelices (Cuenca)

${ }^{43}$ En Augusta Raurica (Augst, Suiza) se halló un anillo de bronce con entalle del mismo tipo en un contexto arqueológico con monedas de Augusto, Tiberio, Domiciano y Marco Aurelio. Véase Riha 1990, 126, Taf. 3.31

${ }^{44}$ Sobre la iconografía de Sócrates en el siglo I a. C así como los entalles con retrato de un filósofo que se conservan en el Cabinet des Médailles de la Bibliothèque Nationale de France en París, véase Vollenweider 1995, 206-237, nº 226 a 272.

${ }^{45}$ En Grecia se utilizaban otras tablas de números, destinadas a facilitar operaciones más complicadas como la multiplicación y la división en las que las líneas paralelas se disponen horizontalmente como en nuestro entalle. El dibujo de un ábaco griego hallado en la isla de Salamis en Guillaume 1877, 2.

${ }^{46}$ Vollenweider 1995, 233.

${ }^{47}$ La imagen representada podría corresponder también al dios Marte. 
Iconografía: El guerrero aparece desnudo y de pie. El cuerpo de frente gira levemente hacia la derecha. La cabeza cubierta por un casco, de perfil hacia la derecha. Un manto le cae por la espalda hasta las rodillas. El brazo derecho levantado y con la mano sujeta una lanza. El brazo izquierdo aparece flexionado y sostiene en la mano un trofeo. Junto a su pierna derecha se representa un casco de amplia cimera y escudo, que se apoya en el suelo. Línea de base.

Una de las variantes de esta representación en glíptica incluye a un guerrero desnudo contemplando un casco, el cual alza con una de sus manos. Este tipo de entalles podría servir de regalo a un joven al inicio de su carrera militar, deseándole el coraje necesario para la lucha ${ }^{48}$.

Paralelos en glíptica: Zazoff 1970, $\mathrm{n}^{\circ}$ 7, Taf.. 2 (Braunschweig); Pannuti 1983, nº 164-165; Guiraud 1995, no $30-31$

Datación: La elección del tema se aleja de los modelos estatuarios y numismáticos tan ampliamente representados en la glíptica. H. Guiraud considera que el guerrero simbolizó mejor la idea de la guerra entre la población que la imagen de un héroe conocido ${ }^{49}$. $\mathrm{P}$. Zazoff piensa que el motivo del guerrero despojado de todas sus armas aparece en la glíptica romana en el siglo II a. C. y encuentra sus antecedentes en el mundo etrusco ${ }^{50}$. Esta pieza presenta uno de los mejores grabados de los entalles catalogados en este trabajo. La habilidad del grabador permitió crear una imagen muy detallista, prestando especial interés en la talla del cuerpo, con los músculos muy resaltados. Por otra parte, destaca el drapeado del manto y los detalles del casco. La cronología del entalle, atendiendo a sus características estilísticas y a la gran calidad de ejecución, se sitúa a inicios del siglo I d. $\mathrm{C}^{51}$.

\section{1.- Harpokrates con cornucopia} Siglo II d.C.

Ónice. Forma redondeada. Ambas superficies planas y perfil recto con leve bisel cortado hacia el anverso. Medidas: $1,1 \times 0,9 \times 0,2 \mathrm{~cm}$.

$\mathrm{N}^{\mathrm{o}}$ inventario: colección privada

Procedencia: El Hito (Cuenca).

\footnotetext{
48 Sobre este tema, véase Guiraud 1995, 387 y nota 142.

49 Guiraud 1995, 364-365.

${ }^{50}$ Zazoff, P. 1970, 11-12.

${ }^{51}$ C. Wagner y J. Boardman 2003, 59-60 y pl. 58, no 415, 417 y 420 proponen una cronología del siglo I d. C. para los entalles con representación de un guerrero, que se conservan en una colección privada inglesa y que presentan una técnica de grabación muy similar a la pieza de Segobriga.
}

Iconografía: Retrato del dios de perfil izquierdo. Está desnudo. El dedo índice de su mano izquierda se acerca a los labios, gesto característico de las representaciones de Harpokrates y que se interpreta en el mundo greco-romano como una invitación al silencio (Plutarco, de Is. et Os. 378 b-c). Sobre la cabeza lleva una flor de loto. Detrás se representa una cornucopia o cuerno de la abundancia, que sujeta con su brazo derecho.

Harpokrates representa al dios egipcio Horus niño, hijo de Isis. Su culto se introduce en el mundo griego y romano de la mano de Isis y Serapis. Su imagen infantil favoreció su difusión como símbolo del silencio $^{52}$. En Pompeya se conocen algunos ejemplos de amuletos con la imagen de esta divinidad, aunque en alusión a Harpokrates como dios de la prosperidad ${ }^{53}$. La representación de este dios la encontramos también en la numismática de finales del siglo I y primera mitad del II d. C. ${ }^{54}$.

Paralelos en glíptica: Zwierlein-Diehl 1979, n 1373 ( $\sin$ cornucopia); Mandrioli 1987, $\mathrm{n}^{\circ} 250$ (busto sin cornucopia); Guiraud 1988, no 383 (busto); WagnerBoardman 2003, n 229 (de cuerpo entero).

Datación: La representación de Harpokrates en las monedas de finales del siglo I y primera mitad del siglo II d. C debió popularizar su imagen y favorecer su uso en la glíptica. El grabador de este entalle delineó muy bien el busto del dios. Prestó atención al detalle del ojo, boca y nariz, a pesar de quedar semioculta por la flor de loto que lleva en la cabeza. Las manos están bien modeladas, al igual que el adorno de la cabeza y la cornucopia. La técnica de ejecución de esta pieza podría encuadrarse dentro del estilo clásico modelado definido para la glíptica y fechado durante el siglo I y primera mitad del II d. C.

\section{2.- Caballo}

Siglo II-III d. C.

Pesa de telar con marca de entalle.

Medidas: $1,1 \times 0,8 \times 0,15 \mathrm{~cm}$.

$\mathrm{N}^{\mathrm{o}}$ inventario: 01/5000/1031

Procedencia: Foro

\footnotetext{
${ }^{52}$ Sobre los atributos de esta divinidad y la difusión de su culto en la antigüedad véase Tam, Jaeger y Poulin, Lexicon, IV.1, 1988, s. v. Harpokrates, 415- 445. En Lexicon, IV.2, 1988, 242-266 puede verse imágenes del dios documentadas en pintura mural, numismática, cerámica, escultura y gemas, con una cronología que abarca desde el siglo III a. C. hasta el II d. C.

${ }^{53}$ Pannuti 1983, no 107, 350-351.

${ }^{54}$ Una de las primeras representaciones de Harpokrates con cornucopia en la numismática romana la encontramos en las monedas de bronce acuñadas por Domiciano en Alejandría, véase Poole 1964, nº 306, lám. XVII.
} 


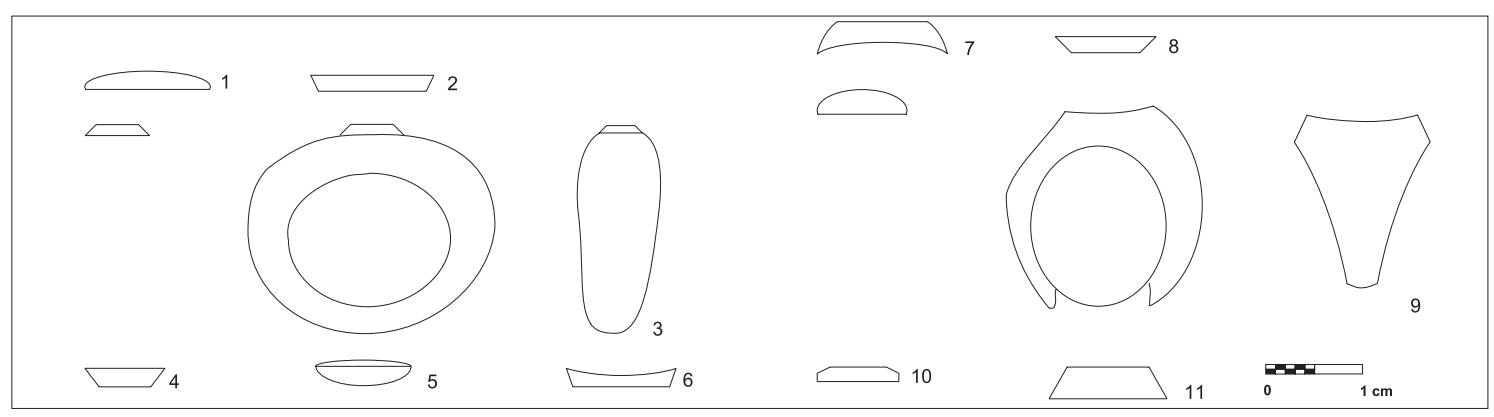

Figura 1. Dibujo del perfil de la forma de los entalles de Segobriga.

Iconografía: Representación de un caballo levantado sobre sus patas traseras, mirando hacia la izquierda. Las patas delanteras no se aprecian.

G. Sena Chiesa considera que la representación de animales sobre gemas es muy frecuente en el mundo romano. Preferentemente, se trata de una producción estándar, en la que se observa un gusto naturalista. Sin duda, la imagen del caballo está asociada al mundo oriental. Algunas de las representaciones pudieron llegar a la glíptica a través de las imágenes conocidas de las monedas, sobre todo de Sicilia y de la Magna Grecia, donde la representación de animales fue particularmente frecuente, aunque también están presentes en la numismática romana ${ }^{55}$.

Datación: Se localizó en el nivel superficial del foro y, por tanto, descontextualizado. Lo interesante de esta pieza es que no conocemos el entalle sino su impronta en una pesa de telar. El conjunto de pesas hallado en Segobriga asciende a la cantidad de 82, de las que sólo 12 presentan una marca incisa realizada antes de la cocción y en la que predomina, sobre todo, el motivo del aspa ${ }^{56}$. Esta pesa de telar constituye una excepción entre los ejemplares recuperados en las excavaciones de Segobriga ${ }^{57}$. Presenta forma paralelepípeda,

\footnotetext{
55 Sena Chiesa, 1966, 344-345.

${ }^{56}$ Los hallazgos de pesas de telar con marca en aspa han aparecido en el Foro ( $\mathrm{n}^{\mathrm{o}}$ inventario: 00/5000/2324; 02/5550/14; $02 / 5591 / 103$; 02/5918/5 y 05/7750/1256), en una vivienda excavada junto a las Termas Monumentales ( $\mathrm{n}^{\circ}$ inventario: 02/8072/21) y en el área del Circo ( $\mathrm{n}^{\circ}$ inventario: 04/9011/1438; 05/9220/161 y 459). El motivo de un círculo se documenta en dos pesas de telar halladas en el área forense ( $n^{\circ}$ inventario 02/5810/47) y en la vivienda anterior ( $\mathrm{n}^{\circ}$ inventario 02/8104/34). El contexto estratigráfico de las pesas con marca incisa de Segobriga apunta a una cronología del siglo IV-V d. C.

57 En Segobriga conocemos otra pesa de telar con marca de entalle, aunque sin imagen ( $\mathrm{n}^{\circ}$ inventario: 02/8104/34). Esta pesa apareció en un contexto bajo-imperial durante la excavación de una de las viviendas situadas en el costado occidental de un edificio de tres naves dedicado probablemente al culto imperial y construido en época flavia.
}

sección cuadrangular y un único orificio de sujeción ${ }^{58}$. La utilización de los entalles como sellos por un taller artesano está documentada sobre distintos tipos cerámicos ${ }^{59}$ y también sobre pesas de telar ${ }^{60}$. G. Rosini, que ha estudiado el conjunto de pondera hallados en Mozia (Sicilia), apunta la idea de que la aparición de algún motivo decorativo en las pesas de telar pueda asociarse no sólo al taller de fabricación sino también a su propietario, a su montaje o incluso a su uso ${ }^{61}$. En este sentido, M. L. Marchi considera que el repertorio de imágenes documentadas en los pondera podrían estar relacionados con la marca de fabricación del producto manufacturado, que serviría de esta manera para reconocer al artesano que lo había tejido ${ }^{62}$. Para acercarnos a la cronología de esta pieza contamos con el motivo del caballo, utilizado de forma reiterada como símbolo de la victoria en la glíptica de finales del siglo II y durante el III d. C. ${ }^{63}$

58 Siguiendo la tipología de las pesas de telar establecida por J. Alarçao y S. da Ponte para los ejemplares hallados en Conimbriga, el ejemplo de Segobriga se incluiría en el Grupo IV. Esta clasificación puede verse en Alarçao-Etienne 1979, 62-64. En un contexto púnico, es interesante el hallazgo de pesas de telar en el interior de dos ánforas en la estancia 39 y 41 de la "Zona A", Isola C del barrio de Porta Sud de Mozia, que G. Rossoni asocia al almacenamiento de las pesas tras el desmontaje del telar. Véase Rossoni, 2002, 317.

59 Algunos ejemplos de marcas de entalles sobre sigillata en Belmont 1977, $\mathrm{n}^{\circ}$ 263, forma Goudineau 27 y n⿳2 264, forma Goudineau 41; sobre barniz negro en Prayon-Gran-Aymerich 1999, 360 y lám. 30-3; sobre ánforas greco-romanas encontradas en Ilion en Panas-Pontes 1998, 223-262. Para España puede verse el artículo de Sotomayor 1988, 253-264.

${ }^{60}$ Marchi 1991, 128-134, $\mathrm{n}^{\circ} 1$ al 8. Las figuras impresas en estas pesas de telar tienen unas dimensiones que rondan los $5 \mathrm{x}$ $5 \mathrm{~cm}$, por lo que la autora las considera estampillas. En el caso de Segobriga, las medidas del motivo $(1,1 \times 0,8 \mathrm{~cm})$ sugieren que la marca se ha realizado con un entalle engarzado en un anillo.

${ }^{61}$ Rossoni 2002, 319-320.

${ }^{62}$ Marchi, 1991, 128. Esta autora se refiere también el carácter votivo y funerario que pudieron tener las pesas de telar, si se tiene en cuenta su presencia en santuarios y en enterramientos.

${ }^{63}$ Sena Chiesa 1978, 115. 


\section{COMENTARIO}

Segobriga fue en época antigua un importante nudo de comunicaciones, donde se cruzaban vías procedentes del valle del Guadalquivir, de Mérida y Toledo en dirección a Valencia y Cartagena. Además, la ciudad fue el centro del control económico y de comercialización de las minas de lapis specularis, lo que permitió su auge económico y su monumentalización a partir de época de Augusto. La colección de entalles de Segobriga es tributaria de los estilos de la moda en Italia y la elección de los temas representados supone una rápida integración de su población en los modos de vida romanos, acrecentada por la llegada de negotiatores vinculados a las explotaciones mineras.

La epigrafía funeraria de la ciudad nos presenta a una sociedad con un importante número de libertos y esclavos, originarios de las provincias orientales del Imperio $^{64}$. Segobriga se muestra así como receptora de inmigrantes, que fueron llegando a la ciudad durante los siglos I y II d. C. para atender las propiedades agrarias, las minas y participar en las tareas relacionadas con el funcionamiento diario, incluso en el plano administrativo. Este aire oriental de la población segobrigense también se intuye en los temas elegidos en algunos de los entalles, como la imagen del caballo ( $\left.n^{\circ} 12\right)$ o el personaje con ábaco griego que aparece en la pieza $\mathrm{n}^{\circ} 9$.

Los entalles que proceden de excavaciones en Segobriga se han hallado en el interior de la ciudad, con la excepción del $n^{\circ} 7$ del catálogo encontrado en la necrópolis tardo-romana. Cinco ejemplares proceden del foro $\left(\mathrm{n}^{\mathrm{o}} 2,4,5\right.$ y 6 y 12$)$, uno del anfiteatro $\left(\mathrm{n}^{\mathrm{o}} 1\right)$ y otro de las termas monumentales $\left(\mathrm{n}^{\circ} 3\right)$.

El conjunto de entalles de Segobriga utilizó el cuarzo y la pasta vítrea como materia prima. Dentro del cuarzo son numerosas las variedades, que reciben el nombre genérico de calcedonias pero que, según su color, se les llama cornalina (rojo), ónice (blanco-negro), jaspe (rojo o verde), etc. La piedra más corriente para la talla de entalles y camafeos durante el período romano fue la cornalina. En Segobriga se ha documentado en dos ocasiones ( $n^{\circ} 5$ y 6 ) con datos cronológicos para una de estas piezas, que permite considerar que la cornalina se empleó en un momento anterior a la $1^{\text {a }}$ mitad del siglo II d. C. Entre las piedras opacas se emplearon el jaspe, el cuarzo y el ónice. El jaspe de color variado fue utilizado en los entalles $n^{\circ} 2,8$ y 9 del catálogo, con una cronología que se sitúa entre el siglo I a. C y el II d. C. El ónice aparece en $l o s n^{\circ} 3$ y 11 y en solo una ocasión ( $\left.n^{\circ} 10\right)$ se ha utilizado una variante, el nicolo, formada por dos colores, muy de moda en época augustea ${ }^{65}$. Por último, la pasta vítrea se documenta en los $n^{\circ} 1$ y 7 del catálogo,

\footnotetext{
${ }^{64}$ Almagro Basch 1984, 437-438.

${ }^{65}$ Guiraud 1988, 361.
}

utilizada a lo largo del siglo III d. C. si tenemos en cuenta el hallazgo de una de estas piezas en el interior de una sepultura de la necrópolis tardo-romana de Segobriga.

La iconografía de los entalles de Segobriga tiene paralelos en muchas colecciones europeas. Destacan las piezas de temas religiosos, donde diosas y dioses se representan en actitudes que se repiten con frecuencia no sólo en entalles, sino también en las monedas, esculturas, pinturas, etc. En dos ocasiones ( $n^{\circ} 2$ y 3 ) se utilizó la imagen de Bonus Eventus, una de las divinidades del panteón romano ligada a la prosperidad. Siguiendo la iconografía greco-romana aparece Minerva, una escena con sátiro, el retrato de Pan y Harpokrates y ( ${ }^{\circ} 4,6,8$ y 11). Junto a las representaciones de divinidades, se encuentra la imagen del águila ( $\left.\mathrm{n}^{\circ} 5\right)$, transformada en símbolo del poder del emperador al aparecer asociada a una corona de laurel.

Los entalles $n^{\circ} 1,7,9$ y 12 presentan imágenes que se aproximan más a la vida diaria, alejándose del simbolismo religioso o de la propaganda imperial. Por otro lado, la pieza $\mathrm{n}^{\circ} 10$ elige el tema de la guerra, con la imagen de un guerrero de pie, provisto de una lanza y con el resto de armas en el suelo. Este tipo de representaciones revela, en opinión de H. Guiraud, cierta libertad del grabador para aludir al tema de la guerra pero evitando utilizar la imagen de Marte ${ }^{66}$.

Los estudios de glíptica romana han establecido distintas corrientes o estilos, atendiendo a la técnica de grabación, que ayudan a fechar los entalles ${ }^{67}$. Durante el siglo I y la primera mitad del siglo II d. C. se desarrolla un estilo clásico modelado, en el que podrían incluirse los números 2, 6 y 10 de la colección de Segobriga. Se caracteriza por la gran realidad que se imprime a las imágenes representadas, donde se presta especial atención a las distintas partes del cuerpo, con la musculatura muy marcada. Un segundo estilo, denominado clásico lineal, abarcaría los siglos I y II d. C. y en él se presta menos atención a los detalles, acentuándose las divisiones entre las distintas partes de las figuras, como en los números 3, 4 y 11 de nuestra catálogo. A partir de estos estilos se produce una evolución hacia la simplificación de los elementos y del trabajo del artesano. Desde la segunda mitad del siglo II d. C. se representan formas redondeadas, los detalles anatómicos se olvidan y los motivos representados son mucho más simples, sobre todo, animales. Esta evolución hacia el esquematismo se

${ }^{66}$ Guiraud 1988, 364-365. Por su parte, Henig 1974, 115 llama la atención sobre el número tan bajo de imágenes relacionadas con la guerra en la glíptica si se compara con la gran cantidad de escenas de carácter guerrero representadas en el arte escultórico romano.

${ }^{67}$ La clasificación de los entalles atendiendo a corrientes estilísticas relacionadas con el estilo de grabación ha sido realizada por varios autores. Una síntesis de estos estilos puede verse en el trabajo de H. Guiraud sobre los entalles y camafeos de la Gallia (1988, pp. 35-56). 


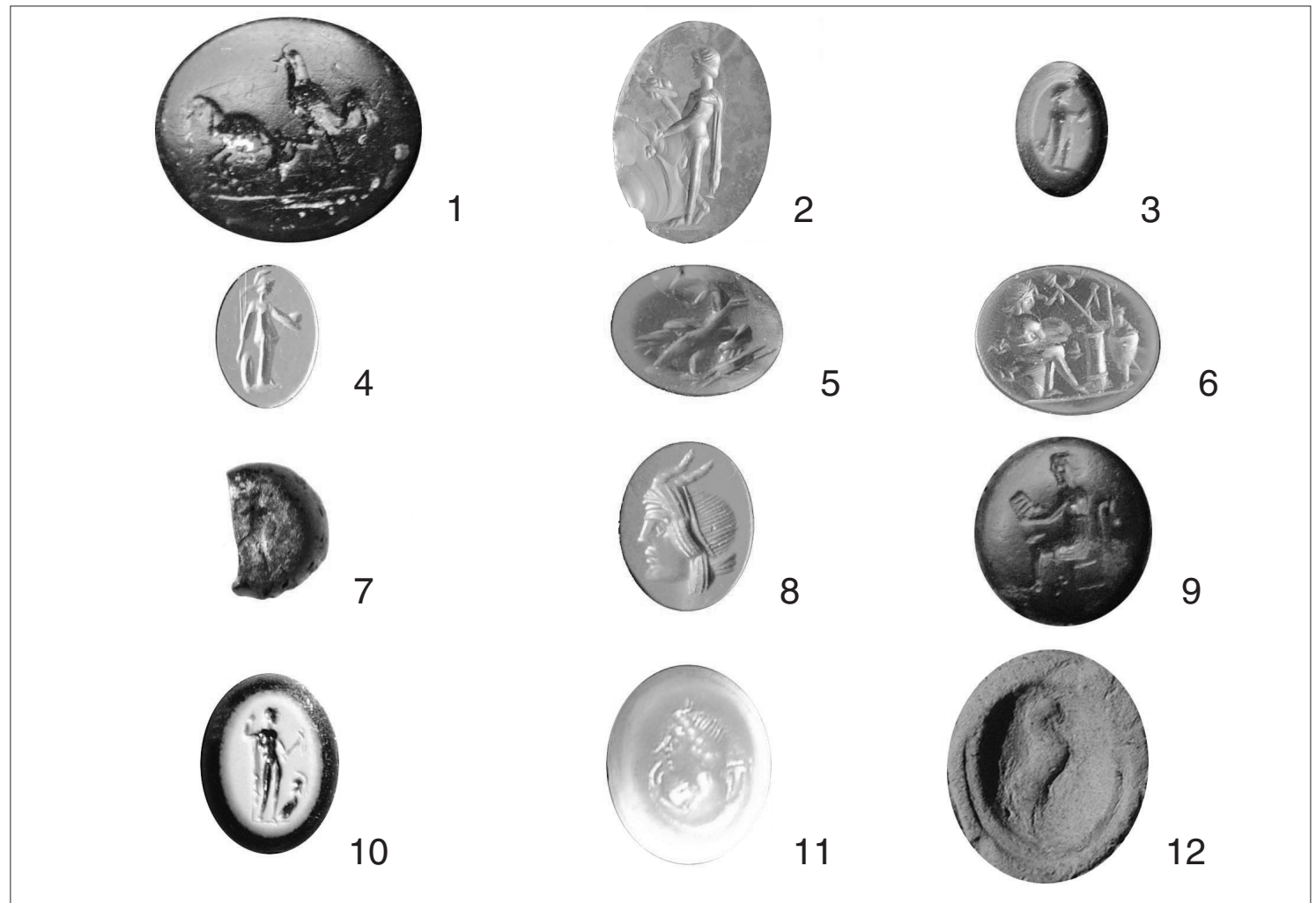

Figura 2. Imágenes representadas en los entalles de Segobriga al doble de su tamaño.

observa en el entalle $\mathrm{n}^{\circ} 7$, que formó parte del ajuar de un enterramiento de la necrópolis tardo-romana de Segobriga.

\section{BIBLIOGRAFÍA}

ABASCAL, J. M., CEBRIÁN, R. Y TRUNK, M. (2004): "Epigrafía, arquitectura y decoración arquitectónica del foro de Segobriga", La decoración arquitectónica en las ciudades romanas de Occidente (Cartagena, 2003), Murcia, pp. 219-256.

ABASCAL, J. M., CEBRIÁN, R., RUIZ, D. Y PIDAL, S. (2004): "Tumbas singulares de la necrópolis tardo-romana de Segobriga (Saelices, Cuenca)", Sacralidad y Arqueología, Antigüedad y Cristianismo, XXI, Murcia, pp. 415-433.

ALARÇAO, J. y ETIENNE, R. (ed.) (1979): Fouilles de Conimbriga, vol. VII, París.

ALMAGRO BASCH, M. (1984): Segobriga II. Inscripciones ibéricas, latinas paganas y latinas cristianas, Madrid.

ALMAGRO-GORBEA, M. Y ABASCAL, J. M. (1999): Segóbriga y su conjunto arqueológico, Real Academia de la Historia, Madrid.

AQUILUÉ, X. (1985): "Algunas consideraciones sobre el comercio africano, Tres facies características de la cerámica común africana en época Alto-Imperial”, Empúries 47, Barcelona.

BELMONT, C. (1977): "Marques sur céramiques sigillées au Musée du Louvre", MEFRA, 89.

BRANDT, E. (1968): Antike Gemmem in Deutschen Sammlungen. Band I. Staatliche Münzsammlung München. Teil 1. Griechische Gemmen von minoischer Zeit bis zum späten Hellenismus, München.

BRANDT, E. (1970): Antike Gemmem in Deutschen Sammlungen. Band I. Staatliche Münzsammlung München. Teil 2. Italische Gemmen etruskisch bis römisch-republikanisch, München.

BRUNEAU, Ph. (1965): "Le motif des coqs affrontés dans l'imagerie antique", Bulletin de Correspondance Hellenique, 89, pp. 90-121.

CASAL GARCÍA, R. (1990): Colección de glíptica del Museo Arqueológico Nacional (Serie de entalles romanos), Bilbao.

DAREMBERG, CH. y SAGLIO, E. (1877): Dictionnaire des antiquités grecques et romaines d'après les textes et les monuments, Paris.

DENEAUVE, J. (1974): Lampes de Carthage. Enciclopedia dell'Arte Antica Classica e Orientale, Roma, 1966.

ERGÜN, N. (1999): "Der Rings als Statussymbol”, Kölner Jahrburch, 32, Köln, pp. 713-725. 
FELLMANN, R. (1983): "Römische Rechentafeln aus Bronze", Antike Welt, 14, pp. 36-40.

FERNÁNDEZ-CHICARRO, C. (1953): "Camafeos y entalles del Museo Arqueológico Provincial de Sevi1la", Memorias de los Museos Arqueológicos Provinciales 1950-1951, Madrid, pp. 60-74.

GERSZTELYI, T. (2000): Antike Gemmen im Ungarischen Nationalmuseum, Catalogi Museo Nationalis Hungarici, Series Archaeologica, III, Budapest.

GUIRAUD, H. (1988): Intailles et camées de l'époque romaine en Gaule: (territoire française), Gallia 48, Supl., Paris.

GUIRAUD, H. (1995): "Intailles de Lons-le-Saunier, Jura", Gallia 52, Paris, pp. 359-406.

HENIG, M. (1974): A Corpus of Roman Engraved Gemstones from British Sites, Oxford.

HENIG, M. (1983): A handbook of Roman Art. A survey of the visual arts of the Roman World, Oxford.

HUMER, F. (2004): Archaeological Park Carnuntum. The Roman city quarter in the open air Museum Petronell, Viena.

KRETZSCHMER, F. (1978), Bilddokumente römischer Technik, Düsseldorf.

KRUG, A. (1995): Römische Gemmen im Rheinischen Landesmuseum Trier, Trier.

LEXICON Iconographicum Mythologiae Classicae, Zürich-Munchen, 1986.

LÓPEZ DE LA ORDEN, Mª D. (1990): La glíptica de la antigüedad en Andalucía, Cádiz.

LORRIO, A. (2001): Ercávica. La muralla y la topografía de la ciudad, Madrid.

MAASKANT-KLEIBRINK, M. (1978): Catalogue of the Engraved Gems in the royal Coin Cabinet. The Hague. The Greek, Etruscan and Roman Collections, La Haya.

MANDRIOLI, A. R. (1987): La collezione di gemme del Museo Civico Archeologico di Bologna, Bolonia.

MARCHI, M. L. (1991): "Pesi da telaio" en Salvatore, M. (ed.), Il Museo Archeologico Nazionale di Venosa, Matera.

MARQUARDT, N. (1995): Pan in der hellenistichen und kaiserzeitlichen Plastik, Bonn.

NOGUERA, J. M., ABASCAL, J. M. Y CEBRIÁN, R. (2005): "Hallazgos escultóricos recientes en el foro de Segóbriga", V Reunión sobre Escultura Romana en Hispania, Preactas, Murcia, pp. 53-71.

OSUNA, M. et alii (1977): Valeria Romana I, Arqueología Conquense III, Cuenca.

PANAS, C. I. y PONTES, H. R. (1998), "Stamped Amphora and Lagynos Handles from Troia (18891995 Seasons)", Studia Troica.

PANNUTI, U. (1983): Museo Archeologico Nazionale di Napoli. Catalogo della collezione glittica, vol. I, Roma.

PLATZ-HORSTER, G. (1984): Die antiken Gemmen im Rheinischen Landesmuseum Bonn, Köln-Bonn.
PLATZ-HORSTER, G. (1994): Die antiken Gemmen aus Kanten II, Köln.

POOLE, R. S. (1964): Catalogue of the Greek Coins in The British Museum, Bologna.

PRAYON, F. y GRAN-AYMERICHG, J. (1999): "Castellina del Marangone (Comune di S. Marinilla, Prov. Roma)", Romische Mitteilungen, 106.

PUGLIESE, G. et alii (1994): Pompei. Pitture e Mosaici, vol. V, Regio VI, parte seconda, Roma.

RIHA, E. (1990): Der römische Schmuck aus Augst und Kaiseraugst, Forschungen in Augst, 10, Augst.

ROSSONI, G. (2002): "Pesi da telaio" en FAMA, $\mathrm{M}^{\mathrm{a}} \mathrm{L}$. (ed.) Mozia. Gli scavi nella "Zona A" dell'abitato, Bari.

SENA CHIESA, G. (1966): Gemme del Museo Nazionale di Aquileia, Padova.

SENA CHIESA, G. (1978): Gemme di Luni, Archaeologica, 4, Roma.

SCHLÜTER, M., PLATZ-HORSTER y ZAZOFF, P. (1975): Antike Gemmen in Deutschen Sammlungen. Band IV. Hannover, Kestner-Museum Hamburg, Museum für Kunst und Gewerbe, Wiesbaden.

SOTOMAYOR, M. (1988): "Fondos de sigillata de Andalucía con marcas interiores de entalles", Homenaje a García-Bellido, Gerión, 1.

SPIER, J. (2001): A Catalogue of the Calouste Gulbenkian Collection of Gems, London.

VOLLENWEIDER, M. L. (1979): Catalogue raisonné des sceaux, cylindres, intailles et camées, vol. II, Mainz-Rhein.

VOLLENWEIDER, M. L. (1995) : Camées et intailles. Tome I. Les Portraits grecs du Cabinet des médailles, Paris.

WAGNER, C. y BOARDMAN, J. (2003): A Collection of Classical and Eastern Intaglios, Rings and Cameos, Studies in Gems and Jewellery, 1, BAR International Series 1136, Oxford.

ZANKER, P. (1992): Augusto y el poder de las imágenes, Madrid.

ZAZOFF, p. (1970): Antike Gemmen in Deutschen Sammlungen. Band III. Braunschweig, Göttingen, Kassel, Wiesbaden.

ZAZOFF, P. (1983): Die antiken Gemmen, Handbuch der Archäologie , München.

ZWIERLEIN-DIEHL, E. (1969). Antike Gemmen in Deutschen Sammlungen, Band. II. Staatliche Museum Preussischer Kulturbesitz Antikenabteilung. Berlin, München.

ZWIERLEIN-DIEHL, E. (1979): Die antiken Gemmen des kunsthistorischen Museums in Wien, München.

ZWIERLEIN-DIEHL, E. (1998): Die Gemmen und Kameen des Dreikönigenschreines. Der Dreikönigenschrein im Kölner Dom, Band I.1, Köln.

Recibido el 13-06-06 Aceptado el 10-09-06 